\title{
LIBERTAD DIVINA, POSIBILIDAD Y CONTINGENCIA EN DUNS ESCOTO
}

Antonio Pérez-Estévez*

SÍNTESE - A vontade humana, em razão da sua indeterminação e da sua capacidade interna de produzir atos volitivos contrários e de querer objetos contrários, é aquilo que nos distingue como seres humanos em relação à natureza e nos faz semelhantes a Deus. A vontade divina, por ser infinitamente perfeita, pode, com um único ato volitivo, querer simultaneamente e produzir objetos contrários (a e -a). Portanto, Deus, no mesmo instante da eternidade, pôde, com a sua potência absoluta, ter querido a e/ou -a, o que implica que pôde ter querido este mundo e/ou outro e outros mundos, que são lógica e realmente possíveis. Esta potência divina para, com um único ato volitivo, querer objetos contrários é a causa da contingência radical de todos os entes criados

PALAVRAS-CHAVE - Vontade. Dndeterminação. Contingência. Vontade divina. Mundos possíveis.
ABSTRACT - Human will, because of its indetermination and internal capacity for producing contrary volitive acts e for willing contrary objects, is that which makes us different from nature and similar to God. The divine will, since it is infinitely perfect, with a sole volitive act can will simultaneously and produce contrary objects ( $a$ and $-a$ ). Therefore, God could have willed in the same instant of eternity, with his absolute potency, a and/or -a, what implies that he could have willed this world and/or another and other worlds, which are logically and really possible. This divine potency for willing, with a sole volitive act, contrary objects is the cause of the radical contingency of all created beings.

KEY WORDS - Will. Indetermination. Contingency. Divine will. Possible worlds.

\section{Voluntad versus naturaleza}

Duns Escoto, teniendo en cuenta el modo que la potencia activa tiene de ejecutar sus operaciones, distingue entre el mundo físico o natural en el que reina la determinación y la necesidad, y el mundo de la voluntad en el que reina la indeterminación y la libertad. Naturaleza y voluntad se le aparecen a Escoto como potencias activas contrarias.

Las potencias naturales, en las que se incluye el entendimiento humano, actúan ante el objeto que las mueve de manera determinada y necesaria, v.g., el agua a 0 grados Celsius se convierte en hielo, el perro con hambre ante la carne no puede abstenerse de comerla y el entendimiento humano, ante un objeto inte-

Universidad Julia/Maracaibo.

\begin{tabular}{l|l|l|l|l|l} 
VERITAS & Porto Alegre & v. 50 & n. 3 & Setembro 2005 & p. 85-93
\end{tabular}


ligible, lo conoce necesaria y naturalmente de manera que no puede no conocerlo o conocer algún objeto distinto. La determinación de la naturaleza es descrita textualmente como

la potencia que está de suyo determinada a actuar de manera que, en cuanto de ella dependa, no puede no actuar cuando no está impedida por algo extrínseco. ${ }^{1}$

El entendimiento, igual que los sentidos, está determinado por su naturaleza a conocer y, ante uno o varios objetos inteligibles, no puede no conocerlos a no ser que algo exterior se lo impida.

El entendimiento cae en el ámbito de la naturaleza, pues por sí mismo está determinado a entender y no tiene en su poder ya sea entender ya sea no entender.

No es, por tanto, el entendimiento racional lo que caracteriza al ser humano y lo distingue de la naturaleza, como se había defendido en la tradición intelectualista aristotélico-tomista. El entendimiento es una potencia natural, intellectus est idem principium cum natura y, en consecuencia, necesariamente determinada, si todas las condiciones se cumplen, para ejecutar su acción propia de entender.

Para Duns Escoto va a ser la facultad o potencia activa volitiva, la voluntad, la que nos distingue esencialmente del mundo natural y nos hace semejantes a la Divinidad, dándonos la capacidad de ser libres, es decir, de elegir o de querer actos contrarios que pueden conducir a objetos contrarios o simplemente de no querer ninguno de esos objetos. La voluntad humana, por su esencial indeterminación, encierra la posibilidad de poder realizar actos volitivos opuestos y, mediante los actos opuestos, tender libremente hacia objetos opuestos ya sea de una manera inmediata, ya sea moviendo otras potencias ejecutoras. ${ }^{2}$ En eso consiste la libertad de la voluntad: a partir de su indeterminación, posee la posibilidad de auto-determinarse y querer los contrarios o no quererlos. El entendimiento humano, decimos, está determinado por el objeto inteligible al que no puede negarse a conocer. El entendimiento, como potencia natural, se encuentra determinado a actuar necesariamente ante la presencia de su objeto. Pero la voluntad es, en sí misma, indeterminada, lo que significa que su opción para actuar no es única y necesaria sino múltiple y contingente: puede realizar este acto volitivo o su contrario y tender a este objeto o a su contrario o no querer ninguna de las dos opciones contrapuestas v.g. puede amar u odiar un mismo objeto e, incluso, ser indiferente ante ese objeto. La indeterminación esencial de la voluntad humana es la

\footnotetext{
Quaestiones subtilissimae in libros Metaphysicorum Aristotelis, liber IX, q. 15, n. 4 (Opera Omnia, Edición Wadding-Vivès, t. VII, p. 609a): aut enim potentia ex se est determinata ad agendum, ita quod quantum est ex se, non potest non agere quando non impeditur ab extrinseco... prima potentia communiter dicitur natura.

2 Lectura I, dist. 39, q. 1-5, n. 45 (Opera Omnia, Edición Vaticana, t. XVII, p. 493): voluntas enim nostra libera est ad actus oppositos (ut ad volendum et nolendum, et amandum et odiandum), et secundo mediantibus actibus oppositis est libera ad objecta opposita ut libere tendat in ea, et tertio est libera ad effectus quos producit sive immediate sive movendo alias potentias exsecutivas.
} 
causa de la posibilidad de ser libres, es decir, de dudar, de poder querer opciones opuestas, y de elegir y tender a una de ellas o no querer ninguna. ${ }^{3}$

\section{Libertad divina, posibilidad y contingencia}

La libertad humana es una libertad que, como todo lo humano y creado, no es absolutamente perfecta. Encierra, en sí misma, algo de perfección y algo de imperfección. El hecho de que la voluntad humana sea libre para actos volitivos opuestos, es una imperfección debido a que no puede realizarlos simultáneamente, lo que entraña receptividad y mutabilidad. El hecho de que la voluntad tenga libertad para tender a objetos opuestos, es una perfección. ${ }^{4}$ En efecto, la voluntad humana está condicionada por el acto concreto que ejecuta y por el objeto al que este acto tiende. En ese mismo instante, la voluntad humana no puede no querer esa acción volitiva y no tender hacia ese objeto. Pero como este acto volitivo y este objeto son queridos contingentemente, la voluntad en otro instante, posterior o anterior, puede, también contingentemente, ejecutar la acción volitiva contraria y tender a un objeto contrario al que ahora quiere y tiende. La imperfección de la voluntad humana por la que quiere y tiende sucesivamente a objetos opuestos, es consecuencia de su mutabilidad. 'Lo blanco puede ser negro' en tiempos distintos y, de manera análoga, 'la voluntad que quiere esto, puede también odiarlo' en tiempos distintos. ${ }^{5}$ Todo objeto querido libremente por la voluntad humana es querido de una manera contingente y, en consecuencia, puede dejar de ser querido por la voluntad para pasar ésta a querer otro objeto distinto, también de una manera contingente. Contingencia y posibilidad son cualidades que acompañan los actos y los objetos queridos por la voluntad libre del hombre y son consecuencia de su radical indeterminación y mutabilidad.

A la libertad de la voluntad sigue también una potencia o posibilidad lógica a la que, sin duda, corresponde una posibilidad real. Esta potencia lógica puede querer opuestos que por no encerrar contradicción puedan ser unidos. ${ }^{6}$ Potencia

3 Quaestiones subtilissimae in libros Metaphysicorum Aristotelis, IX, 15, n. 2. 4-5 (Opera Omnia, Edición Wadding-Vivès, t. VII, p. 607-610).

4 Lectura I, dist. 39, q. 1-5, n. 46 (Opera Omnia, Edición Vaticana, t. XVII, p. 493): in ista libertate voluntatis aliquid est imperfectionis et aliquid est perfectionis: quia quod habeat libertatem ad actus oppositos, hoc est imperfectionis, quia secundum hoc necessario est receptive et mutabilis per consequens (cum non simul habeat actus oppositos); libertas autem ad objecta opposita est perfectionis, quia quod voluntas possit operari circa objecta opposita, non est imperfectionis sed pefectionis...

5 Lectura I, dist. 39, q. 1-5, n. 48 (Opera Omnia, Edición Vaticana, t. XVII, p. 494): una contingentia et possibilitas ut voluntas successive feratur in objecta opposita et haec possibilitas et contingentia consequitur eius mutabilitatem. Secundum hanc possibilitatem 'album est nigrum' in diversis temporibus ut album in a potest esse nigrum in b; unde ista possibilitas consequitur successionem. Et sic etiam haec vera in sensu divisionis 'voluntas amans illum, potest odiare illum'.

6 Lectura I, dist. 39, q. 1-5, n. 49 (Opera Omnia, Edición Vaticana, t. XVII, p. 494): Potentia logica non est aliqua nisi quando extrema sic sunt possibilia quod non sibi invicem repugnant sed uniri possunt, licet non sit possibilitas aliqua in re; et sic fuit haec vera antequam mundus esset 'mundus potest esse'; et si intellectus aliquis creatus tunc fuisset, vere potuisset dixisse hoc, scilicet 'mundum posse esse', et tamen nulla fuit realitas in re correspondens extremis. 
lógica es la capacidad de querer posibles lógicos, es decir, posibles que no encierren contradicción. Yo en este instante quiero A, pero como lo quiero contingentemente, mi voluntad también en este mismo instante posee la posibilidad de dejar de quererlo, es decir, de no querer $A$ y odiarlo, para querer $-A$. La posibilidad o potencia - no el acto - de querer algo opuesto a lo que ahora quiero, se da simultáneamente con mi querer actual. ${ }^{7}$ Escoto la llama potencia o posibilidad lógica, porque esa posibilidad es, en este instante, sólo posibilidad aunque responda a una potencia real de la voluntad. Esta potencia lógica, que es real, acompaña siempre a la voluntad y es la razón de que pueda cambiar sucesivamente los actos de volición y los objetos queridos. La voluntad está unida a sus actos y objetos de una manera contingente $y$, en consecuencia, encierra siempre la posibilidad lógi$\mathrm{ca}$, porque en ese mismo instante no puede querer otro objeto distinto, y real, porque dicha posibilidad de cambiar sus actos volitivos para producir otros actos volitivos distintos y querer objetos distintos, existe permanentemente en la voluntad. Este mundo, antes de ser creado, era un posible lógico inteligible para cualquier entendimiento humano de la misma manera que cualquier otro mundo distinto a éste que no encierre contradicción y al que le repugne ser necesario. Cualquier entendimiento, antes de la creación, podría haber afirmado que 'este mundo era posible', de igual manera que hoy cualquier entendimiento puede afirmar que 'otro mundo distinto a éste es posible'. La posibilidad o potencia de actos volitivos distintos está siempre y esencialmente encerrada en la indeterminación de la voluntad libre.

La voluntad divina es infinitamente perfecta e infinitamente libre. Su libertad carece de las imperfecciones de la voluntad humana. Es sumamente indeterminada para realizar cualquier acción en razón de su actualidad ilimitada.

Comparémosla con la voluntad humana. La voluntad humana puede realizar actos volitivos opuestos por los que quiere objetos distintos - quiere $A$ y quiere no $A$ - pero sucesivamente. Quiere A y no $A$, pero en actos distintos y en momentos sucesivos. Ya explicamos que tal libertad humana encerraba algo de perfección y algo de imperfección. Querer objetos distintos y opuestos es una perfección, pero quererlos con actos volitivos distintos y en tiempos sucesivos, es una imperfección, debido a que se da un cambio o mutación en nuestra voluntad. No podemos entender así la libertad de Dios. Dios puede igualmente querer efectos u objetos distintos: es una perfección. Pero los quiere sin cambio alguno en su voluntad, es decir, con una única volición. La voluntad humana cuando quiere un objeto está limitada por tal objeto y no puede, en ese mismo instante, querer otro objeto distinto. Puede querer otro objeto sucesivamente, en tiempos distintos, lo que supone que la voluntad cambia y produce otro acto volitivo distinto. Dios no puede cam-

Lectura I, dist. 39, q. 1-5, n. 50 (Opera Omnia, Edición Vaticana, t. XVII, p. 495): haec possibilitas logica non est secundum quod voluntas habet actus successive, sed in eodem instanti nam in eodem instanti in quo voluntas habet unum actum volendi, in eodem et pro eodem potest habere oppositum actum volendi - in eodem instanti in quo vult a potest nolle a, nam velle pro illo instanti et in illo instanti non est de essentia ipsius voluntatis nec est eius passio naturalis, igitur consequitur ipsam per accidens... 
biar y, por tanto, no puede producir un nuevo acto volitivo distinto. Dios en un solo acto volitivo $y$, por tanto, en el mismo instante quiere objetos opuestos, quiere a la vez $A$ y no $A$.

Detengámonos a analizar el siguiente texto descriptivo de la libertad divina:

Voluntas divina libera est ad effectus oppositos producendos. Sed haec non est prima libertas, sed requirit aliam priorem; primam autem libertatem, quae est in nobis (quae est respectu actuum oppositorum), non potest voluntas divina habere, quia haec est imperfectionis et arguit mutabilitatem, voluntas autem divina non potest habere nisi unicam volitionem, et ideo unica volitione potest velle opposita objecta, nam eius unica volitio est praevalens omnibus volitionibus creatis respectu diversorum, sicut eius unica intellectio respectu omnium intellectorum creaturarum. Unde eius unica volitio habet praevalentiam respectu omnium volitionum tendentium in diversa objecta, quia quaelibet nostra volitio limitata est ad suum objectum. Si igitur ponitur aliqua una illimitata, quae est volitio divina, illa poterit oppositorum objectorum esse. Est igitur libertas voluntatis divinae quod ipsa unica volitione potest tendere in opposita objecta, et in infinitum liberius quam nos diversis volitionibus... (Lectura I, Edición Vaticana, t. XVII, p. 496). ${ }^{8}$

Descompongamos en proposiciones:

1.1 La voluntad divina es libre para producir efectos opuestos.

1.2 Ésta no es la libertad primera, la cuál se da en nosotros, pero que no puede darse en la voluntad divina, y es la libertad de (realizar) actos (volitivos) opuestos. Incluye imperfección y mutabilidad.

1.3 La voluntad divina no puede tener actos o voliciones opuestas - Su voluntad se identifica con Su acto volitivo en el que no puede darse sucesión ni cambio - sino que con una única volición puede querer efectos u objetos opuestos. Su volición vale más que todas las voliciones creadas respecto a los objetos diversos.

1.4 Toda volición nuestra está limitada a su objeto. Una volición ilimitada como la divina, puede querer objetos opuestos.

1.5 La libertad de la voluntad divina es tal que con la misma volición (y desde el mismo instante de la eternidad) puede tender a objetos opuestos y de una manera infinitamente más libre que nosotros con las diversas voliciones.

La voluntad humana es libre para realizar actos volitivos opuestos y querer o buscar objetos opuestos. Juan es libre para con un acto volitivo a querer el objeto

Por su importancia, transcribimos la continuación de este texto Lectura I, dist. 39, q. 1-5, n. 54 (Opera Omnia, Edición Vaticana, t. XVII, p. 497): voluntas divina, licet non possit habere actus oppositos (quia voluntas est eadem cum sua volitione) tamen voluntas divina unica volitione vult in aeternitate lapidem esse et potest in aeternitate velle lapidem non esse vel potest nolle lapidem esse, ita quod voluntas divina in quantum est operativa ad intra, et sic prior effectu, potest producere et non producere objectum; ut sicut est possibilitas in voluntate nostra respectu actus volendi - et logica et realis - in eodem instanti et pro eodem respectu eiusdem, ita etiam voluntas divina, quae in quantum operativa praecedit se ut productiva, potest in eodem instanti aeternitatis et pro eodem instanti aeternitatis velle et nolle aliquid, et sic producere aliquid et non producere. 
a y, después, con el acto volitivo -a querer el objeto -a. La voluntad humana está limitada al objeto querido y no puede querer simultáneamente dos objetos distintos. Querer otro objeto supone producir otro acto volitivo en tiempo distinto.

La voluntad divina es libre para querer objetos opuestos, pero no con actos volitivos distintos, sino con un único acto volitivo. En Dios no se dan actos volitivos opuestos porque no puede darse sucesión ni cambio: con un único acto de su voluntad, es libre de querer a y -a simultáneamente desde toda la eternidad. Dios es infinitamente más perfecto, más libre y más poderoso que el ser humano. La voluntad divina no está limitada al y por el objeto querido; puede simultáneamente querer a y -a.

El ser humano (Juan) quiere, con un acto volitivo a, este objeto a. Después puede querer, con un nuevo acto volitivo distinto (-a) y en tiempo distinto, aquél otro objeto -a. Y tal posibilidad o potencia para cambiar de acto volitivo y de objeto querido, es lógico-real, tal como ya hemos dicho. Dios, por el contrario, puede querer, con un único acto volitivo y simultáneamente, $A$ y/o $-A(A \vee-A ; A \wedge-A)$. Esto significa que Dios pudo desde el mismo instante de la eternidad:

1. querer solo $A$;

2. querer sólo - $A$ (siendo - $A$ un solo objeto);

3. querer sólo - $A$ (siendo - $A$ objetos múltiples, v.g., $a, b, c, d, \ldots$ );

4. querer simultáneamente $A$ y $-A$ (siendo $-A$ un solo objeto);

5. querer simultáneamente desde toda la eternidad $A$ y $-A$ (siendo $-A$ objetos múltiples v.g. $a, b, c, d, e, f, \ldots)$;

6. querer la existencia sucesiva de $A$ y $-A$ (siendo $-A$ un solo objeto);

7. querer la existencia sucesiva de $A$ y - $A$ (siendo - $A$ objetos múltiples).

$\mathrm{Si}$, como hace Duns Escoto, pensamos que posible-lógico, para la voluntad divina, puede ser un mundo y suponemos que $A=$ este universo creado y que $-A$ $=$ otro $\mathrm{u}$ otros universos creados, tendremos la siguiente serie de posibilidades lógico-reales que pudieron darse en el mismo instante de la eternidad: ${ }^{9}$

1. Dios pudo querer solo este universo creado;

2. Dios pudo querer sólo otro universo creado distinto. (No lo hizo);

3. Dios pudo querer sólo otros universos creados distintos a éste. (No lo hizo);

4. Dios pudo querer la existencia simultánea de este universo creado y de otro universo creado distinto. (No conocemos la existencia de otro universo distinto, pero su existencia es un posible lógico-real);

5. Dios pudo querer la existencia simultánea de este universo y de otros universos distintos. (No conocemos la existencia de otros universos distintos, pero tal existencia múltiple es una posibilidad lógico-real);

\footnotetext{
9 Lectura I, dist. 39, q. 1-5, n. 49 (Opera Omnia, Edición Vaticana, t. XVII, p. 494): Potentia logica non est aliqua nisi quando extrema sic sunt possibilia quod non sibi invicem repugnant sed uniri possunt, licet non sit possibilitas aliqua in re; et sic fuit haec vera antequam mundus esset 'mundus potest esse'; et si intellectus aliquis creatus tunc fuisset, vere potuisset dixisse hoc, scilicet 'mundum posse esse', et tamen nulla fuit realitas in re correspondens extremis.
} 
6. Dios pudo querer la existencia sucesiva de este universo y de otro universo distinto. (No podemos conocer la existencia de tal universo futuro, pero es una posibilidad lógico-real);

7. Dios pudo querer la existencia sucesiva de este universo y de otros muchos universos distintos. (No podemos conocer esa existencia múltiple futura, pero es una posibilidad lógico-real).

Eliminadas a posteriori las hipótesis 2 y 3, debido a que Dios, aunque pudo querer sólo otro u otros universos distintos a éste en el que vivimos, no lo hizo porque, al menos, quiso este universo nuestro, nos quedan las posibilidades reales $1,4,5,6$ y 7 , a saber:

Dios pudo querer solo la existencia de este universo creado;

Dios pudo querer la existencia simultánea de este universo creado y de otro universo creado distinto;

Dios pudo querer la existencia simultánea de este universo y de otros universos distintos;

Dios pudo querer la existencia sucesiva de este universo y de otro universo distinto:

Dios pudo querer la existencia sucesiva de este universo y de otros universos distintos.

La existencia de otro u otros mundos distintos a éste, simultáneos o sucesivos, es una posibilidad lógico-real, de acuerdo a la doctrina de Escoto. En el instante de la eternidad pudo, con un único acto volitivo, querer y crear, además del universo al que pertenecemos, otro u otros universos distintos, simultáneos o sucesivos al nuestro. Tales universos, aunque desconocidos hasta este momento para nosotros, son lógicamente posibles y realmente posibles. Su existencia encierra una posibilidad lógica - tal posibilidad no encierra contradicción - y real: Dios pudo, con su potencia absoluta, realmente querer y crear tales universos. Es decir, Dios en el mismo instante en que creó este mundo, pudo realmente haber creado otro u otros mundos distintos a éste, simultáneos o sucesivos. Conocemos, desde la visión escotista, su posibilidad lógica y real. Pero su existencia, si se da, no la conocemos. Por eso, continúan siendo, para nosotros, posibles lógico-reales.

La voluntad libre y omnipotente de Dios es la causa y la razón de que los seres existan y existan contingentemente. La voluntad omnipotente y absoluta de Dios tiene un límite para la creación de seres creados: el principio de no contradicción. ${ }^{10}$ Dios puede crear todo lo posible, es decir, todo aquello que formalmente no encierre contradicción y al que le repugne ser necesario, v.g., no puede hacer un cuadrado redondo. Pero el crear distintos mundos simultáneos o sucesivos, con distintas leyes físicas y/o morales, no encierra en sí mismo contradicción alguna y

${ }_{10}$ Todo posible, sometido al principio de no contradicción, implica: (1) la no repugnancia formal para ser, y (2) la repugnancia para tener por sí mismo un ser necesario. Para Escoto, es tan contradictorio unir dos formalidades contradictorias como el que algo creado o hecho tenga un ser necesario: possibile... est illud cui non repugnat esse et quod non potest ex se esse necessario... (Ordinatio I, dist. 43, q. un., n. 7; Opera Omnia, Edición Vaticana, t. XVII, p. 354). 
es, por tanto, un posible lógico-real. Lo imposible está separado de lo existente por el amplísimo ámbito de lo posible, el cual, para convertirse en existente, necesita que la voluntad divina haya decidido desde toda la eternidad producirlo. El posible se subdivide por tanto en puro posible (lógico-real) que jamás pasará a la existencia y el posible existente, el cuál en algún momento se concretará en la existencia, a saber, cuando la libre y omnipotente voluntad divina lo haya decidido. Nosotros conocemos algo, una parte de lo existente; de hecho, hemos venido ampliando, en intensidad y en extensión, la esfera del universo conocido en la medida que la técnica ha mejorado los instrumentos de visión como los microscopios y los telescopios, y ha logrado ensamblar móviles que alcanzan hoy cuerpos extraterrestres como la Luna, Marte y Júpiter. Pero es prácticamente imposible que alcancemos a conocer todo lo existente. Lo puro posible, lógico y real, abarca toda la esfera de lo que, en sí, no encierra contradicción y que, por tanto, pudo haber sido creado por Dios desde toda la eternidad. Forma parte, con lo imposible, de la inmensa esfera del ente de razón. Intentemos un esquema de todo el ámbito óntico escotista:

1. Entes de razón:

1.1 Los entes imposibles: podemos hablar de ellos y, al pensarlos, descubrimos su incoherencia formal interna. Ni son lógica y realmente posibles ni pueden, por tanto, existir.

1.2 Entes puro posibles (lógica y realmente posibles): que en sí no encierran contradicción y a los que les repugna tener un ser necesario. La voluntad libre y omnipotente de Dios no decidió crearlos. Esfera amplísima, aunque sea difícil concretar la coherencia lógica de mundos físicos o morales distintos al que conocemos como existente.

2. Entes reales y existentes: aquellos que no encierran en sí contradicción y además la voluntad libre y omnipotente de Dios decidió, desde toda la eternidad, crearlos en algún momento.

2.1 Entes que existen pero que no conocemos, v.g., universos existentes pero desconocidos para nosotros. Para nosotros continúan siendo entes o universos puro posibles.

2.2 Entes que existen y son conocidos como tales por nosotros, v.g., el universo en el que habitamos y del que cada día conocemos más. Los únicos de los que estamos seguros que existen.

La potencia divina absoluta y libre para, con un único acto volitivo, querer objetos distintos y contrarios, es la razón y la causa por la que todo lo creado mundo o mundos y/o las sustancias individuales que los constituyen - sea contingente, es decir, pueda ser de otra manera y/o dejar de ser. Nada creado es necesario, ni siquiera ex suppositione, como quería Tomás de Aquino. De hecho, el orden moral establecido ha sido modificado en distintas ocasiones y temporalmente por la Divinidad, tal como lo describe la Biblia: a Abraham le ordena matar a su hijo Isaac, a los Israelitas apropiarse de los vasos de oro y plata de los Egipcios, al Profeta le ordena fornicar con una prostituta. El orden moral 
establecido por los 7 últimos mandamientos que tratan de regular las relaciones entre seres humanos - los 3 primeros se refieren a las relaciones del ser humano con Dios - es tan contingente como todo orden físico creado. ${ }^{11} \mathrm{Ni}$ son principios prácticos absolutamente necesarios, ni conclusiones absolutamente necesarias: la bondad que prescriben no es necesaria para la obtención del fin último ni la maldad prohibida nos separa necesariamente del fin último. Por eso, cualquiera de esos 7 mandamientos puede Dios revocarlo o declarar cómo han de entenderse ${ }^{12}$. Y revocar una ley significa, para Duns Escoto, establecer una nueva ley y un nuevo orden. Lo que no puede Dios es hacer lícito algo que permanece ilícito o, manteniendo el precepto, actuar en contra del precepto.

Quiero llamar la atención sobre la distinción entre el concepto de contingencia escotista y el concepto de contingencia de Avicena, autor del que el franciscano fue deudor en muchos aspectos. La contingencia escotista, como hemos visto, es una característica del libre actuar divino y, como consecuencia de esa acción libre de Dios, se convierte en radical propiedad ontológica de todo lo creado. Dios actuó, actúa y actuará ad extra de manera contingente, es decir, pudo, puede y podrá actuar de otra manera o simplemente no actuar, lo que hace que lo creado sea así pero haya podido y pueda ser de otra manera o dejar de ser. La contingencia aviceniana, por otro lado, constituye la esencia misma de los seres posibles (id autem quod possibile est esse, possibile est non esse) los cuales, una vez que tienen una Causa necesaria que les da el ser, se convierten en seres necesarios de hecho ${ }^{13}$. El universo físico de Avicena, a pesar de su existencia eterna, está marcado por la limitación esencial de poder no-existir, aunque nunca deje de existir. Es decir, el universo creado de Avicena es, en su esencia, contingente o indiferente a ser y a no-ser pero se convierte en necesario una vez que recibe su existencia (que es un accidente) de la Causa Primera necesaria. ${ }^{14}$

11 Quaestiones in librum III Sententiarum, dist. 37, q. un., n. 6 (Opera Omnia, Edición Wadding-Vivès, t. XV, p. 825b): Talia non sunt quaecumque praecepta secundae tabulae, quia rationes eorum quae ibi praecipiuntur vel prohibentur, non sunt principia practica simpliciter necessaria, nec conclusiones simpliciter necessaria. Non enim in his, quae praecipiuntur ibi, est bonitas necessaria ad bonitatem ultimi finis, convertens ad finem ultimum; nec in his quae prohibentur, est malitia necessario avertens a fine ultimo.

${ }^{12}$ Op. cit., Liber III, dist. 37, q. un., n. 1 (Opera Omnia, Edición Wadding-Vivès, t. XV, p. 785b: dispensatio enim non est facere, quod stante praecepto liceat facere contra praeceptum; sed dispensare est revocare praeceptum, vel declarare qualiter debeat intelligi.

13 Avicenne, Le Livre de science I, Paris, 1955, p. 136: Toute chose... donc (pour qu'elle puisse exister), il faut qu'elle soit possible par elle-même, qu'elle devienne nécessaire à condition qu'il y ait une cause nécessaire qui la produisse.

${ }^{14}$ Ver una explicación más detallada de la contingencia de lo posible en Avicena en: Pérez Estévez, A., La materia, de Avicena a la Escuela Franciscana, Ediluz, Maracaibo, 1998, cap. 3, pp. 75-102. 